\title{
Methods Of Teaching English Language Vocabulary To The First-Year Uzbek Students
}

\author{
${ }^{1}$ Jalilova Miray Rustambekovna, ${ }^{2}$ Allanyazov Marat Bakhavedinovich, ${ }^{2}$ Jumaniyazova Enajon \\ Qutimovna, ${ }^{1}$ Duldulova Nigora Ashimovna, ${ }^{1}$ Meyliyeva Gulnoza Minggirovna \\ ${ }^{1}$ Lecturer, Department of Foreign languages, Tashkent Institute of Architecture and Civil Engineering, Tashkent, Uzbekistan. \\ ${ }^{2}$ Senior Lecturer, Department of Foreign languages, Tashkent Institute of Architecture and Civil Engineering, Tashkent, \\ Uzbekistan.
}

\begin{abstract}
Assimilation is the ability to use or recognize vocabulary fluently in speech. Possession or mastery means knowing the level of skill. Simple cognition refers to the ability to memorize the meaning of a word or to recognize its form. The consequence of knowing is mastery, that is, the use of a unit of language in speech. Vocabulary control is done through direct speech activities, not through special inquiries. When speaking on a topic, reading / listening comprehension creates sufficient conditions to test the student's lexical skills. Despite the fact that the goal of studying a foreign language lexicon was to conduct speech, working on lexical units during the period of acquaintance (Presentation, Presentation) and exercise (training, activation) was the primary task, when going to the stage of application, speech serves as the primary, and lexical as the engine, that is, "building material". Consequently, it is natural for lexical skills to be included in the composition of speech skills.
\end{abstract}

Keywords:

foreign language, learners, well-structured, knowledge, skills, abilities, speech, positively assess, informants, alphabetical order Article Received: 18 October 2020, Revised: 3 November 2020, Accepted: 24 December 2020

\section{Introduction}

In the education system of Uzbekistan, the first-year students, graduates of secondary special education, are expected to have higher levels according to the European Standards of Foreign Language Proficiency. Persons who are expected to specialize in a foreign language during the period are expected to acquire language skills at the C1 level from English language. Summarizing these requirements and levels, first-year foreign language learners should have the following skills: the applicant can understand the main ideas of complex texts on specific and abstract topics, including technical discussions in the field of specialization; can interact with each other with a level of dialogue and self-awareness, which is not a problem for both parties; can develop a clear and detailed text on topical issues, providing advantages and disadvantages in different options; can understand many demanding and long texts, can express himself fluently; can use language flexibly and effectively for social, scientific and professional purposes; can demonstrate the ability to produce clear, well-structured, detailed text on complex topics, to organize speech well, and to use connectors and a unifying device (Trim, 2011).

\section{Methodology}

In order to determine the extent of knowledge, skills and abilities of students in the process of learning a foreign language vocabulary, errors and interferences in their speech, a small questionnaire and test exercises from freshmen were held. The survey was attended by first-year Uzbek students (24 informants) studying English at the Tashkent Institute of Architecture and Civil Engineering

The following questions were presented in the questionnaire:

1. To what extent do you assess your language skills in Foreign language?

a) i Apply freely in the process of speech;

b) I can use in colloquial speech;

c) I understand, but I speak with difficulty.

2. Do you use mother tongue during the study of English texts?

a) I do not apply translation cases; 
b) I translate text into native language verbally and with difficulty;

c) I translate the whole text into my native language.

3. Where or how do you prefer to learn a foreign language basically?

a ) at the University / lesson

b) outside the lesson

C) independent

4. Can you use academic lexicon in the teaching process with your teachers and peers?

a) I can freely understand and apply academic lexicon;

b) I understand the instructions of the teacher, but I find it difficult to understand the instructions in the textbooks;

c) I can not understand the instructions in the learning process without explanation in the native language;

5. To what extent can you initiate questions and conversations on the lesson?

a) armed with a leisurely conversation on the lesson;

b) only if it is necessary, that is, in an incomprehensible situation, I will join the conversation through the question;

c) I do not interfere with the course discussion because of insufficient lexical skills.

6. Can you name all the objects and actions that you use in the learning process?

a) Express all your objects and work-actions;

b) I use the dictionary when naming the educational objects and instructions

c) I can not name teaching materials and subjects in English.

7. In which language do you prefer the terms of the text in English textbooks?

a) only in academic English;

b) with sample in English;

c) in the Uzbek language

8. Do you respond to the instructions of the teacher with an absolute physical reaction (Total physical response), that is, Can you perform the workactions that are asked without words immediately dynamic?

a) I can immediately return a dynamic response; b)work-time is needed to be understood before the action is taken;

c) I can not answer the instructions if the teacher does not comment in Uzbek.

9. Does the differences in the education system of the Uzbek and English hinder in fully articulating your thoughts?

a) Yes;

b) in rare cases it hinders;

c) No

10. Does the abundance of signifiers in the English language in relation to the Uzbek language interfere with the full understanding of the lexicon? (for example, read-reading, skimming, scanning; learn, study)

a) does not interfere with full understanding;

b) I understand with the help of context;

c) I can not understand until I apply the signifiers in practice.

Twenty-four informants assessed their language skills and demonstrated the following indicators:

Graph \#1

\begin{tabular}{|c|c|c|c|}
\hline & A & B & C \\
\hline 1. & $21 \%$ & $42 \%$ & $37 \%$ \\
\hline 2. & $37 \%$ & $54 \%$ & $9 \%$ \\
\hline 3. & $87 \%$ & $4 \%$ & $9 \%$ \\
\hline 4. & $58 \%$ & $42 \%$ & $0 \%$ \\
\hline 5. & $63 \%$ & $37 \%$ & $0 \%$ \\
\hline 6. & $37 \%$ & $63 \%$ & $0 \%$ \\
\hline 7. & $50 \%$ & $37 \%$ & $13 \%$ \\
\hline 8. & $54 \%$ & $46 \%$ & $0 \%$ \\
\hline 9. & $0 \%$ & $67 \%$ & $33 \%$ \\
\hline 10. & $29 \%$ & $58 \%$ & $13 \%$ \\
\hline
\end{tabular}

From the general indicators, it can be concluded that the majority of informants - 55\% of informants positively assess their knowledge of language skills and learning vocabulary, about $45 \%$ of students reacted neutrally, doubting the state of their knowledge, negative conclusions were almost not observed. After examining the students 'attitudes toward the level of knowledge of the academic vocabulary through the questionnaire, a 40- 
question test was taken to determine their lexical layer and possible interference patterns

(Appendix \# 2).

1. Choose the odd one from the below words:
A. bleachers
B. stadium
C. cafeteria
D. teachers' lounge

2. Read the definition below and find out to which word it belongs to.

A book or set of books containing many articles arranged in alphabetical order which deal either with the whole of human knowledge or with a particular part of it.
A. dictionary
B. manual
C. guidebook
D. encyclopedia

3. Find out the synonym of "locker" from the given options
A. shelf
B. wardrobe
C. cupboard
D. safe

4. Change the underlined word with the appropriate equivalent.

Erik starts infant school in September.
A. nursery school
B. elementary school
C. high school D. college

Change the underlined word with the appropriate equivalent.

It is a frame rucksack with a belt and padded shoulder straps.
A. handbag
B. backpack
C. pencil case
D. lunch box

5. Which of the below words are not derived from the other parts of speech?
A. Intonation
B. permission
C. attention
D. fiction

6. Find out the mis-collocation in the sentence: I can't come out. I am studying. I am passing an examination tomorrow.
A. come out
B. studying
C. passing
D. examination

7. Find the definition of physics

A. The scientific study of matter and energy and the effect that they have on each other.

B. Classes at school in which children do exercise and learn to play sport, or the area of study relating to such classes.
C. The systematic study of the structure and development of language in general or of particular languages.

D. The study of relationships between people living in groups.

8. The first lesson on the for Monday is history.
A. course
B. curriculum
C. timetable D. class

9. Lora from the University of London.
A. left
B. finished
c. studied

D. graduated

10. Anyone who caught will be immediately disqualified from the exam.
A. cheating
B. vandalizing
c. leaving D. correcting

11. Replace the underlined word with the appropriate word.

John can easily detect errors in the context.
E. Is cover
B. write
C. read D. copy out

12. Choose the odd word out of the given words
A. spell
B. enunciate
c. pronounce D. write

13. Choose the appropriate form of the word. I passed the exam, but I am still waiting to get my
A. certifying
B. certitude
C. certification D. certified

Which of the sentences below are affirmative?
A. Pass the book, please.
B. John loves reading.
C. Could you open the window, please?
D. You are not listening, are you?
14. Choose the appropriate form of the word. I did six hours of for the test, and I still failed.
A. revision
B. revisal
C. revising
D. revised

15. If you need to the teacher's attention, just put your hand up.
A. pull
B. attract
C. capture
D. draw
16. Make sure you _ your homework before you go out.



A. make
B. solve
C. write
A. make
B. bring
C. take
D. do
D. understand

17. Could I a suggestion? Why not have piano lessons?
A. have
B. do
C. put
D. make

18. I really don't the point of taking the exam when you are not ready for it.
A. take
B. see
C. have

D. mind

19. I'll meet you at the school gates during the lunch
A. break
B. gap
C. interval
D. pause

20. Do you think you could pass that book to me, please?
A. under
B. through
C. over
D. in

21. Mrs. Dawson said that we are our lesson in the library next Monday.
A. having
B. making
reading
D. going

C.

22. In English yesterday, we had a discussion different cultures.
A. around
B. about
C. for
D. from

23. my opinion, math's shouldn't be a compulsory subject.
A. from
B. to
C. at

D. In

When you the exam tomorrow, try to stay calm and relaxed.
A. make
B. write
C. take

D. answer

24. My dad wants me to go to university, but I'm in minds about it.
A. my
B. two
C. some

D. different

25. I still have a lot about the English language.
A. learning
B. to learn
C. for
learning
D. of learning

26. If the examiner can't sense of your writing, you'll get a low mark.
27. I hadn't studied, so when the teacher asked me I had idea.
A. none
B. no
C. even

D. not

The test session in the second half of the constructive part was mainly aimed at determining the level of knowledge of the educational vocabulary, the cases of lexical interference that can be observed in the speech of Uzbek students. According to the test results of the students, the overall results were as follows:

Graph\#2

\begin{tabular}{|c|c|c|c|c|c|}
\hline $\begin{array}{l}\text { The } \\
\text { numb } \\
\text { er of } \\
\text { stude } \\
\text { nts }\end{array}$ & $\begin{array}{l}\text { The } \\
\text { numb } \\
\text { ers of } \\
\text { right } \\
\text { possi } \\
\text { ble } \\
\text { answ } \\
\text { ers }\end{array}$ & $\begin{array}{l}\text { The } \\
\text { right } \\
\text { answ } \\
\text { ers }\end{array}$ & $\begin{array}{c}\text { The } \\
\text { actua } \\
1 \\
\text { num } \\
\text { ber } \\
\text { of } \\
\text { error } \\
\mathrm{s}\end{array}$ & $\begin{array}{l}\text { The } \\
\text { avera } \\
\text { ge } \\
\text { numb } \\
\text { er of } \\
\text { incorr } \\
\text { ect } \\
\text { answe } \\
\text { rs per } \\
\text { stude } \\
\text { nt }\end{array}$ & $\begin{array}{c}\text { Level } \\
\text { of } \\
\text { master } \\
\text { y of } \\
\text { student } \\
\text { s' } \\
\text { vocabu } \\
\text { lary }\end{array}$ \\
\hline 24 & 720 & 457 & 263 & 11 & $63,4 \%$ \\
\hline
\end{tabular}

Practical analysis and errors and omissions can be summarized as follows:

1. Cases of lexical interpersonal interaction-the effect of the lexical system of the Uzbek language on the lexical system of the English language; cases of direct translation of words;

2. Let's not have knowledge of the surface of the new word;

3. Insufficient knowledge of words (collocation), which receive a special union;

4. The connotative meanings of the word in Foreign languages, that is, the inability to distinguish the word signifiers;

5. Inadequacies allowed in the case of the legalization and morphological structure of the word; 
6. Inability to apply the correct form of the word in the context;

7. The propensity of students to choose between words unfamiliar in response; ignorance of the semantic structure of the word, inability to think critically;
8. Inability to distinguish between common (hyponym) and special (hyponym) meaningful words.

The proportion of errors allowed above is described in the diagram below:

Diagram

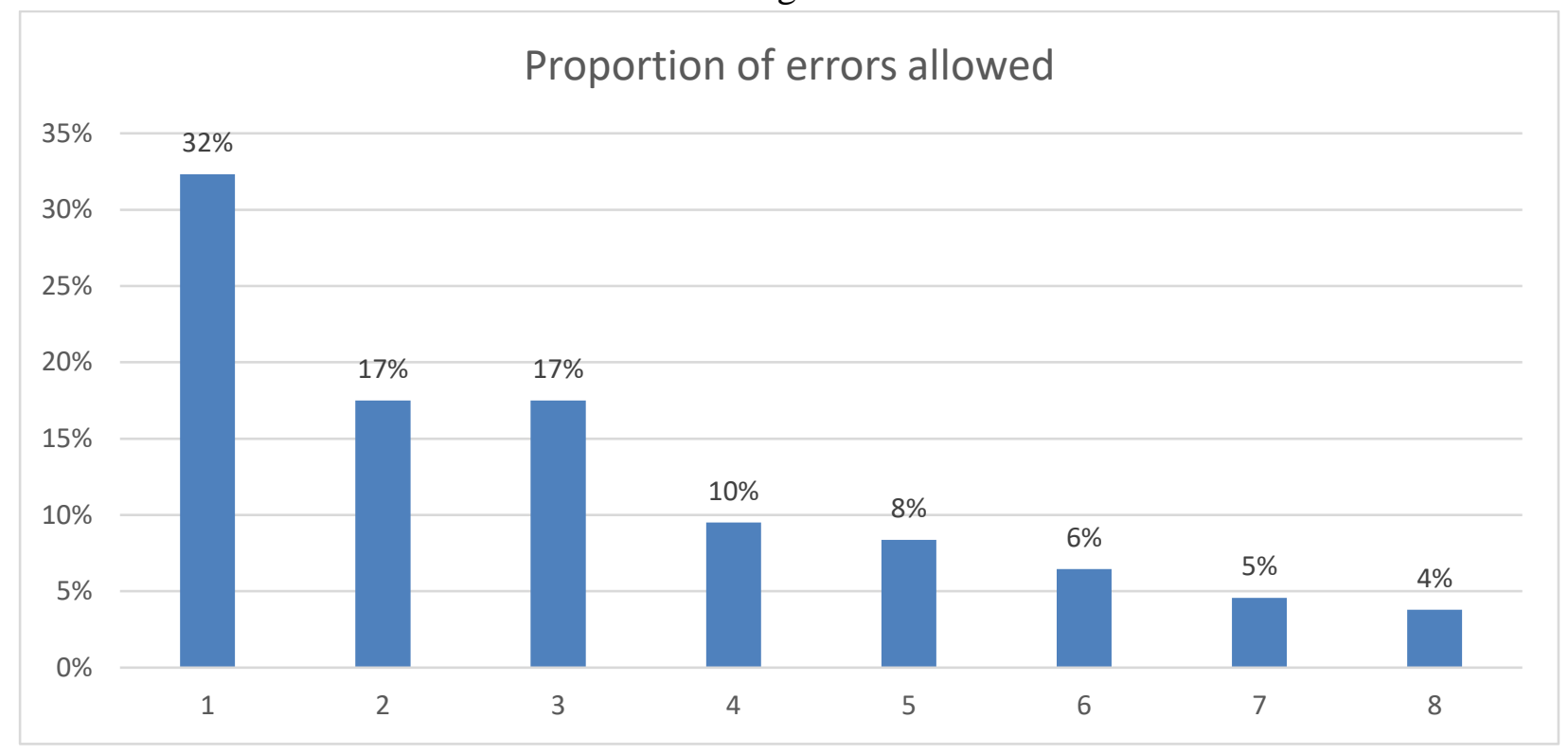

It turned out that the level of knowledge of English vocabulary among first-year Uzbek students specializing in foreign languages is unsatisfactory (63.4\%). In addressing this issue, it would be appropriate to pay special attention to teaching students vocabulary in the early stages of higher education. The following conclusions were drawn from the practical analysis of the constructive part: - The need for systematic selection of lexical material;

- The need to integrate lexical and linguocultural material into the process of teaching foreign languages;

- To develop a system of science-based exercises for Uzbek students to increase their knowledge of English lexicon on the concepts of this lexical layer and to prevent interference in speech.

The level of mastery of English vocabulary by Uzbek students of the $1^{\text {st }}$ year students of Tashkent Institute of Architecture and Civil Engineering was found to be relatively unsatisfactory, and in order to overcome this problem, summarizing their shortcomings and needs, became the basis for the development of a typology of exercises on the lexical layer of the English language.

It is necessary to organize the educational process on each subject on the basis of established principles. Principles of teaching - these are the laws that the teacher should apply in the process of training. The methodology of teaching a foreign language is most primarily based on the following generally accepted principles developed by didactics:

1) educational principles of Education,

2) Science,

3) consciousness,

4) activity,

5) systematization

6) understanding,

7) to take into account the individual characteristics of the students.

The system of exercises is based on the concept of language learning. The exercise theories I recommend in this regard are structured in the above study theories. (Dzhosupav, 1991:239). These principles can not be used at one time in the 
process of training. For example, such principles as educating education, science, taking into account the individual characteristics of students serve to carry out such tasks as creating conditions for students ' interest in learning, educating in the spirit of human values, while at the same time the principle of taking into account the individual characteristics of students is necessary to organize the educational process through the management

In the following years, such principles as communication, inherent only in the teaching of a foreign language, the justification of education for oral speech, the differentiation and the complex organization of teaching, language material, have emerged. At the same time, such principles as consciousness, activity, vision, motivation of the educational process, put forward by didactics, also play an important role in the teaching of a foreign language, since the implementation of any rational action takes place through the transition from thinking to practice. Therefore, the present time attaches importance to the formation of students ' intellectual activities in foreign language curricula and teaching aids. It is also desirable to take into account the influence of the phenomenon of language interaction in the conscious assimilation of reading material.

The principles of activity, consciousness of teaching are connected with the implementation of the unity of practice with theory, in the teaching of a foreign language, from practice to theory at the initial stage, that is, the acquisition of oral speech, then the teaching of the rule, in the middle and upper stages, the formation of a rule, then speech, is envisaged first.

The principle of problem teaching is a method of teaching, which seeks ways to independently perform lexical, grammatical, phonetic tasks given from a foreign language, forcing scientific thinking, research.

Teaching students to think independently and perform tasks begins with the creation of a problem situation through the assignment. But this task forces the student to remember the material he studied before, to think on this basis.
Problem teaching is closely related to the principle of activity, because the more welldeveloped the memory, thinking of the students, the more they show activity in mastering their material. For example, the independent work of students, which they perform during the course of the lesson, is carried out in the following forms, which are organized both orally and in writing, on mastering, strengthening the teaching material:

1. Perform written and oral exercises on the training material;

2. Question and answer on educational material;

3. Organization of work in pairs through cards drawn up on the study material;

4. Perform test assignments on the basis of educational material;

5. Execution of problem assignments on educational material;

6. To teach the mastering of instructional material with the help of technical tools, visual aids.

Since the main purpose of teaching a foreign language is to teach speaking, listening comprehension, reading and writing in the second language, its teaching methodology differs from some principles of teaching methodology in other disciplines. In particular, the following principles are purely methodical principles inherent in the teaching of a foreign language:

a) the principle of communicatively,

b) the principle that education is based on the predominance of oral speech,

C) the principle of organization by differentiating education,

g) the principle of Organization of the educational process,

d) the principle of intensification of educational activities of students (Hoshimov, 2003:25).

The basis of Foreign Language Teaching is the teaching of communicative, this process provides for the formation of speech activity in a foreign language, the teaching of speech, speech, hearing comprehension, reading, writing statement of thought and the formation and development of student's cognitive activity.

Teaching communication in a foreign language is carried out in the form of communicative 
situations. This place is given special attention to communicative situations that can occur in the life of the student. Although the student has mastered the rule of the language well, he may not lack the skills to speak in that language, to refer his thoughts to the attention of the interlocutor. In this place, special attention is paid not only to the formation of linguistic competence (capacity) of students, but also to the formation of communicative competence. The student will examine the attitude or expression of opinion to the information given in the instructional material in various natural and artificial communicative situations. In these aspects, the principle of communicatively harmonizes with the method of functional approach or the principle of oral speech cultivation in the educational process.

The principle of problem learning in the scientific literature on the current method of teaching foreign language has led to the emergence of a new teaching theory such as teaching with projectors. In particular, the training with projects will focus on the solution of a particular part of a common project by dividing the students into groups.

The conduct of the teaching in the communicative direction in turn depends on the activity of the students, also on the motivation of the instructional material. Activism and motivation, as noted above, is carried out through the effective use of teaching techniques and the proper organization of extracurricular work.

The use of differentiated teaching methods and techniques in teaching speaking, hearing comprehension, reading and writing is understood. For example, when teaching to speak, homological and dialogical speech, analytical and synthetic reading in reading, when teaching graphics and Orthography, which is a written form of language, it is necessary to form various skills and skills to teach all types of speech activities. In turn, the use of various methods, methods and tools for the formation of various qualifications and skills will give a positive result.

The principle of Education based on the cultivation of oral speech implies the assimilation of educational material through oral speech. And the teaching of reading and writing is organized on the basis of mastered oral material. Due to the fact that only hearing perception is involved in such an organization of education, some scientists oppose this principle.

The principle of Education based on the cultivation of oral speech implies the assimilation of educational material through oral speech. And the teaching of reading and writing is organized on the basis of mastered oral material. Due to the fact that only hearing perception is involved in such an organization of education, some scientists oppose this principle.

But the principle of differentiation teaching denies teaching through speech on the same basis for students of all ages. The harder the learning material is, the more chances of teaching it on an oral basis will be so limited that hearing perception becomes more difficult than seeing perception.

The principle of complex organization of the educational process provides for the organization of speech activities in various forms by linking phonetic, lexical, grammatical material. The complex organization of the educational process requires the joint implementation of educational goals (practical, educational, developmental).

The principle of intensification (acceleration) of students ' educational activities is closely related to the principles of activity, motivated education. Intensification of students ' educational activities is carried out in the following ways::

- effective use of training time;

- the use of effective methods and methods in the training process;

- to take into account the age characteristics, memory, attention, thinking and mastering abilities of students in the use of methods and techniques, etc.

Teaching the lexical composition of the language is the basis of any foreign language teaching. The system of lexical directed exercises is based on the following principles (Serova: 2013:92) :

1) the study of the active and passive minimum should be based on students ' knowledge and communication needs and activities; 
2) mastering the lexical base should depend on the cognitive processes (perception, attention, imagination, memories, thinking) of students;

3) the process of mastering the lexical asset and the passive minimum should be regarded as the process of information and knowledge associated with the acquisition, collection, storage, use of lexical data and lexical units;

4) the exercises included in the system should correspond to the objectives of teaching a foreign language in the institution in the field of linguistics and should correspond to the process of knowledge and the process of developing the relevant skills and abilities;

5) specially directed lexical content studied should be organized in accordance with the word combinations with the concept, the exact word combinations with the concept in the tenures;

6) assimilation of lexical units with an active and passive feature can be attributed to different types of students (communicative, linguistic, sociolinguistic, discursive, socio-cultural, etc.) should be based;

7) mastering effective and understandable vocabulary should be distinguished from the point of view of its operating approach, with its communicative direction;

8) active and passive minimum units students should have a number of problematic speech and communicative problem solving aspects based on linguistic-creative thinking;

9) the system of exercises should be built taking into account the principle of the positive impact of different types of speech activities on each other in the educational process;

10) in general, the system of lexically oriented exercises and its components are aimed at the formation of lexical competence of the future specialist.

Thus, methodical methods and rules that form lexical skills in teaching the students of the Uzbek audience to the lexical system of the English language must be observed and these activities must be directed to the fulfillment of the above requirements. The following tasks are given in the exercises to fulfill these requirements:
- To perform the action in which the teacher says the name in a foreign language;

- To guess its meaning from the word definition;

- To find the subject matter of the said words;

- To say the meaning of the words separated by accents in the native language;

- Divide the heard words into word categories.

- Listening to the core and derivative words, write separately.

- Put down the dropped word / word combination;

- To find and Mark meaningful, contradictory words in harmony with each other;

- Reading words that demonstrate or exclude certain rules of reading;

- Separate writing of the composition of compound words;

- To determine which word category the given word belongs to;

- To open the meaning of the word by distinguishing the elements of the word construction;

- To reveal the meaning of the word by finding the suffix and suffix of the word; to determine the words according to affixes;

- Divide words into categories, depending on the different characters (subject, meaning, features such as the root or derivative, conjugation);

- Parsing words that belong to the subject or do not belong to it;

- Move word combinations that are suitable for or different from the native language from the text;

- Support word-building verbal and written sentences;

- To draw a question to the words that are drawn or highlighted at the bottom;

- Identify and correct writing of an incorrect word in a given sentence;

- Speaking the read text with the participation of a new word, etc.

The following assignments can be given in the exercises for teaching the English Language Teaching lexicon.

\section{Conclusion}

In order to create a system of exercises on the teaching lexicon of the English language, first 
of all, a test on the topic of knowledge was conducted from the students of the Uzbek auditory. The total number of test takers was 24 and the total number of questions was 30 . The Test consisted of multiple-choice type questions and included a variety of questions related to students ' familiarity with vocabulary, interpersonal situations in the English lexical of the native language, and the ability to correctly select the form and meaning of words.

According to the results of the tests conducted in the 2 first phase groups, the errors made by the students were calculated and the level of knowledge on the total $\mathrm{Fe}$ was determined.

To prevent possible interpersonal situations that may arise due to the results of Test assignments and different aspects of the lexical system in the two languages; it was aimed to compile exercises on the teaching lexicon that serves to develop communicative competence of students.

Exercise is a kind of activity that is performed regularly, aimed at mastering some kind of speech activity. In the methodological literature, the variety of exercises, their typology was approached differently by different criteria; hence their classification is also different. But the main three exercise groups occupy the most oily place (Djusupov, 1991: 196-198): a) exercises aimed at studying the structure of the language; $b$ ) exercises aimed at studying the dynamics of the language; d) exercises aimed at developing speech activity.

The principle of intensification (acceleration) of students ' educational activities is closely related to the principles of activity, motivated education. Intensification of students ' educational activities is carried out in the following ways::

- effective use of training time;

- the use of effective methods and methods in the training process;

- to take into account the age characteristics, memory, attention, thinking and mastering abilities of students in the use of methods and techniques, etc.

Exercises aimed at preventing this condition have been formulated on topics where interpersonal problems may arise;
As much as possible, the contexts inherent in the English and Uzbek culture were chosen and introduced into the exercises.

In accordance with the state standard of education and the knowledge base of the students, exercises of difficulty corresponding to the higher level were given.

\section{References}

[1] Mirolyubov A.A. Methodology or linguodidactics of foreign languages. Foreign languages at school. 2005. № 2.

[2] Speech at the XIV session of the Oliy Majlis. -T.: Uzbekistan, 1999. - 370 p.

[3] Passov E.I. The basics of the communicative method of teaching foreign communication. - M., Russian language 1989, - p. 144-145.

[4] Sainazarov H. Teaching the vocabulary of the English language in the senior grades of the Uzbek school: Cand. diss. - L., 1982.

[5] Serova T.S., Chainikova G.R. System of exercises for the development of lexical competence: article. - M .: Professional education, 2013. - c 92-93.

[6] Starodubseva OG Tipi exercises for the formation of lexical patterns of usina speech in a language university: article. Scientific and pedagogical review. Pedagogical Review. 2013.2

[7] Sternin IA, Sternina MA UDC: Vidi and methods of comparative studies of vocabulary. - 2016. - p. 66-67.

[8] Shansky N.M. Lexicology of the modern Russian language. - M: 1972

[9] Shatilov S.F. Salomatov, K.I. Professiogram of a foreign language teacher. - 1977.

[10] Sherbak ZA Requirements for the educational-methodical complex in the English language as a tool for ensuring the quality of the lesson and the quality of education. - M .: Prosveshenie, 2012 .-- p. 2-3.

[11] Shchukin A.N. Methodology as an educational, scientific and practical 
dissipation. // Methods of teaching Russian as a foreign language. Ch. I / Ed. E.G. Azimov. -M., 2004.

[12] Asher J. Txe Total Physical Response Approach then second language learning. Modern Language Magazine, 1969.

[13] Buranov J., Muminov A. A practical course in English Lexicology. - Tashkent: "Ukituvchi", 1990. - b. 4-5

[14] Cambridge Advanced Learners Dictionary: Txird Edition. - Cambridge University Press, 2008.

[15] Giznburg R., Kidekel S. A Course in Modern English Lexicology. - M: 1979

[16] 16.Hindmarsh, R. Cambridge English Lexicon: .a graduated word sheet for materials writers and course designers. Cambridge: Cambridge University Press. 1980

[17] O'ojiev A. Lexicology of the Uzbek language. - Tashkent, 1981 